\title{
Basic Fibroblast Growth Factor as a Growth Inhibitor for Cultured Human Tumor Cells
}

\author{
Lothar Schweigerer, Gera Neufeld, and Denis Gospodarowicz \\ Cancer Research Institute, University of California Medical Center, San Francisco, California 94143
}

\begin{abstract}
Basic fibroblast growth factor (bFGF) stimulates the proliferation of many cells and it is found in a wide variety of normal or transformed tissues. As demonstrated here, bFGF is also present in cultured human Ewing's sarcoma cells. Unexpectedly, however, bFGF isolated from these cells inhibits their own proliferation, indicating that bFGF can act as an endogenous (autocrine) growth inhibitor for cultured Ewing's sarcoma cells. Since bFGF also inhibits the proliferation of some further tumor cells, but stimulates that of others, it can be considered a bifunctional regulator of tumor cell proliferation. The autocrine growth-inhibitory effect of bFGF in Ewing's sarcoma cells may explain the low mitotic activity of Ewing's sarcomas.
\end{abstract}

\section{Introduction}

Tumor cells, unlike their nontransformed counterparts, can proliferate in the presence of little or no exogenous growth factors. This is probably due to their ability to produce, as well as to respond to, their own growth factors (1). One of the growth factors thought to act in this manner is basic fibroblast growth factor (bFGF), ${ }^{1}$ a peptide mitogen of $M_{\mathrm{r}}$ of 16,500 , which stimulates the proliferation of a wide variety of normal or transformed cells (2). In fact, bFGF is synthesized in and can stimulate the proliferation of cells derived from human embryonal rhabdomyosarcoma (3), a small cell childhood tumor $(4,5)$. We therefore wished to determine whether a

Dr. Schweigerer's present address is the Institute for Experimental Pathology, German Cancer Research Center, 6900 Heidelberg, Federal Republic of Germany. Address reprint requests to Dr. Schweigerer, Institute for Experimental Pathology, German Cancer Research Center (DKFZ), Im Neuenheimer Feld 280, 6900 Heidelberg, Federal Republic of Germany. 1987.

Received for publication 2 March 1987 and in revised form 6 May

1. Abbreviations used in this paper: aFGF, acidic fibroblast growth factor; BCE, brain-derived capillary endothelial; bFGF, basic fibroblast growth factor; DMEM, Dulbecco's modified Eagle's medium; FGF, fibroblast growth factor.

J. Clin. Invest.

(c) The American Society for Clinical Investigation, Inc. $0021-9738 / 87 / 11 / 1516 / 05 \$ 2.00$

Volume 80, November 1987, 1516-1520 similar mechanism might exist in cells derived from other small cell childhood tumors, such as Ewing's sarcomas.

\section{Methods}

Cell culture. Stock cultures of SK-ES1 cells were maintained in gelatinized $10-\mathrm{cm}$ tissue culture dishes containing $10 \mathrm{ml}$ of culture medium, i.e., Dulbecco's modified Eagle's medium (DMEM) supplemented with calf serum $(10 \%)$ and antibiotics $(6,7)$. All other cell lines were maintained as indicated in the legend to Table $I$.

Cell proliferation assays. Cells were seeded at the indicated densities into $35-\mathrm{mm}$ dishes containing $2 \mathrm{ml}$ of their respective medium and every other day received either $10 \mu \mathrm{l}$ aliquots of samples to be tested or no additions. After various times, the cells were dissociated and counted with a particle counter (Coulter Electronics Inc., Hialeah, FL) (8).

Purification of SK-ESI cell-derived bFGF. SK-ES1 cells were grown to confluence in gelatinized $530-\mathrm{cm}^{2}$ tissue culture dishes (Nunc, Roskilde, Denmark) containing culture medium $(6,7)$. Cells $\left(1.8 \times 10^{9}\right)$ were trypsinized, washed twice with ice-cold phosphatebuffered saline (PBS) $/ 0.01 \%$ bovine serum albumin (BSA), resuspended in $10 \mathrm{mM}$ Tris- $\mathrm{HCl}(\mathrm{pH} \mathrm{7.0)/2} \mathrm{M} \mathrm{NaCl}$, and sonicated for 2 min at $4^{\circ} \mathrm{C}$. The $\mathrm{pH}$ was adjusted to 4.5 ; the cell lysate was incubated for $1 \mathrm{~h}$ at $4^{\circ} \mathrm{C}$ and then centrifuged $\left(15 \mathrm{~min}, 4^{\circ} \mathrm{C}, 50,000 \mathrm{~g}\right)$. The supernatant, diluted sixfold with distilled water, was adjusted with $\mathrm{HCl}$ to $\mathrm{pH} 7.0$ and run on a heparin-Sepharose column $(1.2 \times 1.3 \mathrm{~cm})$ preequilibrated with $10 \mathrm{mM}$ Tris- $\mathrm{HCl}$ buffer (pH 7.0) containing 0.6 $\mathrm{M} \mathrm{NaCl}$ (9). Aliquots of the fractions eluted with the same buffer containing $0.6,1.0,2.0 \mathrm{M} \mathrm{NaCl}(9-11)$ were examined for their abilities to stimulate the proliferation of brain-derived capillary endothelial (BCE) cells as previously described (8). All of the bioactivity was eluted with $2.0 \mathrm{M} \mathrm{NaCl}$, resulting in a 3,000-fold purification of the crude extract. The bioactive fractions were pooled and stored at $-70^{\circ} \mathrm{C}$.

Preparation of anti-bFGF antibodies. Rabbits were repeatedly injected (12) with pituitary-derived bFGF (9). The antiserum obtained from one rabbit (Ede) was purified by protein A-Sepharose affinity chromatography (13), and the IgG fractions containing the anti-bFGF antibodies were stored at $-70^{\circ} \mathrm{C}$. The anti-bFGF antibodies, but not control antibodies, are able to inhibit bFGF-induced but not acidic fibroblast growth factor (aFGF)-induced proliferation of capillary endothelial cells (14). They do not cross-react with aFGF or unrelated peptides like insulin, transferrin, epidermal growth factor, thyroglobulin, and cytochrome $c$ in a radioimmunoassay using ${ }^{125}$ I-bFGF as the ligand (14).

Binding of ${ }^{125}$ I-labeled bFGF to SK-ES1 cells. SK-ES1 cells and ${ }^{125}$ I-labeled bFGF ( ${ }^{125}$ I-bFGF) (15) were incubated with or without unlabeled compounds in 24-well tissue culture dishes (Costar, Data Packaging Corp., Cambridge, MA) containing $0.25 \mathrm{ml}$ of DMEM $/ 0.1 \%$ BSA. After $3 \mathrm{~h}$ at $4^{\circ} \mathrm{C}$, binding was terminated by washing each well twice with ice-cold PBS $/ 0.1 \%$ BSA. Cells were then lysed by adding $0.4 \mathrm{ml}$ of lysis buffer (PBS containing NP-40 [0.2\%] and BSA 
[0.1\%]) per well, and the radioactivity in the lysate was determined with a gamma counter.

\section{Results}

Ewing's sarcoma, a most common tumor of adolescents, develops primarily in the pelvis and femur (4). Like embryonal rhabdomyosarcoma, it belongs to the so-called small cell childhood tumors $(4,5)$. Although its histogenesis is still a matter of controversy, a vascular endothelial cell origin has been proposed (5). In view of our recent demonstration that bFGF can act as a self-stimulating (autocrine) growth factor for vascular endothelial (14) or embryonal rhabdomyosarcoma (3) cells, it was of interest to determine whether a similar mechanism might exist in Ewing's sarcoma cells.

To examine this possibility, we used the human SK-ES1 Ewing's sarcoma cell line $(6,7)$ that, under the conditions employed (see legend to Fig. 1), adhered tightly to the tissue culture dishes. Extracts prepared from SK-ES1 cells were subjected to heparin-Sepharose affinity chromatography, a method suitable for the rapid and selective purification of bFGF (9-11), and the fractions eluted were then examined for their abilities to stimulate the proliferation of bFGF-dependent target cells $(3,8,9)$. In fact, the SK-ES1 cell extract con-
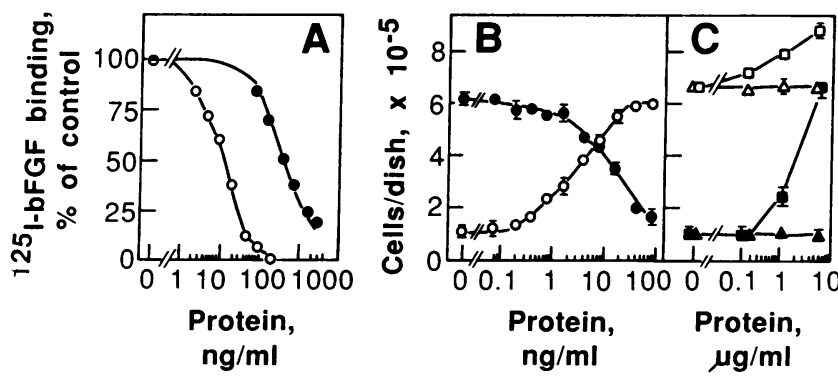

Figure 1. Effect of various concentrations of partially purified SK-ES 1 cell extract on $(A){ }^{125} \mathrm{I}-\mathrm{bFGF}$ binding to BHK-21 cell membranes, $(B)$ the proliferation of capillary endothelial or SK-ESI Ewing's sarcoma cells, and $(C)$ the proliferation of SK-ES1 cells in the presence of anti-bFGF antibodies or control antibodies. $(A)^{125} \mathrm{I}$ bFGF ( $3 \mathrm{ng} / \mathrm{ml})$ and BHK-21 cell membranes (16 $\mu \mathrm{g}$ of protein) were incubated for $30 \mathrm{~min}$ at $21^{\circ} \mathrm{C} \mathrm{(15)} \mathrm{in} \mathrm{the} \mathrm{presence} \mathrm{or} \mathrm{absence} \mathrm{of}$ the indicated concentrations of dialyzed partially purified SK-ES1 cell extract (๑) or native pituitary-derived bFGF (9) (0). Specific binding, which represents bound ${ }^{125} \mathrm{I}-\mathrm{bFGF}$ that was displaced by an excess of unlabeled bFGF $(200 \mathrm{ng} / \mathrm{ml})$, was determined as described (15). Values represent the means of triplicate determinations (SD $<5 \%$ ). (B) Bovine brain-derived capillary endothelial (BCE) (8) (O) or SK-ES1 Ewing's sarcoma cells (•) were seeded at densities of 2 $\times 10^{4}$ or $4 \times 10^{4}$ into native or gelatinized $35-\mathrm{mm}$ dishes, respectively. Every other day, they received either DMEM/0.5\% BSA containing no additions or various concentrations of partially purified SK-ES1 cell extract, as indicated. BCE or SK-ESI cells were counted after 5 or $7 \mathrm{~d}$, respectively, with a counter (Coulter Electronics Inc.) (8). (C) SK-ES1 cells were seeded at a density of $4 \times 10^{4} /$ gelatinized $35-\mathrm{mm}$ dish. Every other day, the dishes first received the indicated concentrations of rabbit anti-bFGF antibodies $(\square, \square)$ or rabbit control antibodies $(\Delta, \Delta)$ (affinity-purified IgG fraction, Flow Laboratories, Inc., McLean, VA) and then DMEM/0.5\% BSA containing partially purified SK-ES1 cell extract $(40 \mathrm{ng} / \mathrm{ml}$, final concentration) (closed symbols) or no additions (open symbols). SK-ES1 cells were counted after $7 \mathrm{~d}$ as described above. Values in $(B)$ and $(C)$ represent the means $( \pm \mathrm{SD})$ of triplicate determinations. tained material able to stimulate cell proliferation. All of the material was retained by heparin-Sepharose columns and eluted as a single peak of bioactivity with $2.0 \mathrm{M} \mathrm{NaCl}$ (see legend to Fig. 1). This chromatographic behaviour is indistinguishable from that of bFGF (9-11), suggesting that the partially purified cell extract that eluted with $2.0 \mathrm{M} \mathrm{NaCl}$ contained bFGF.

This possibility was examined by a fibroblast growth factor (FGF) radioreceptor binding assay using BHK-21 cell membranes (15). Although this assay is less sensitive than FGF bioassays, it allows the specific and precise determination of FGF (15). Indeed, the partially purified cell extract, like native bFGF, inhibited the binding of ${ }^{125} \mathrm{I}-\mathrm{bFGF}$ to the FGF receptor (Fig. $1 A$ ). Furthermore, like bFGF, it stimulated the proliferation of capillary endothelial cells (Fig. $1 B$ ).

Surprisingly, however, the partially purified SK-ES1 cell extract inhibited the proliferation of the same cell line (SKES1) it was purified from, as demonstrated by cell proliferation (Fig. $1 B$ ) or $\left[{ }^{3} \mathrm{H}\right]$ thymidine incorporation assays (not shown). The partially purified SK-ESI cell extract also inhibited the proliferation of SK-ESI cells seeded into extracellular matrixcoated dishes (16) containing either serum-supplemented medium or serum-free medium supplemented with high density lipoproteins $(750 \mu \mathrm{g} / \mathrm{ml})$ and transferrin $(25 \mu \mathrm{g} / \mathrm{ml})$ (7) (not shown).

It was conceivable that the inhibition of SK-ES1 cell proliferation was due to bFGF. If so, the inhibition should have been blocked by anti-bFGF antibodies that neutralize the biological activity of bFGF, but not that of aFGF (14), a closely related mitogen $(11,17)$. Indeed, the inhibition of SK-ES1 cell proliferation by the partially purified SK-ESI cell extract was completely blocked by anti-bFGF antibodies, but not by control antibodies (Fig. $1 C$ ). In the absence of the partially purified SK-ES1 cell extract, the control antibodies had no influence on cell proliferation, whereas the anti-bFGF antibodies induced an increase in cell densities (Fig. $1 C$ ). These results indicate that bFGF is present in the partially purified SK-ES1 cell extract, that it is responsible for the inhibition of SK-ES1 cell proliferation, and, further, that bFGF can act as an endogenous growth inhibitor for SK-ES1 Ewing's sarcoma cells.

These results were substantiated by the demonstration that native pituitary-derived bFGF (9) also inhibited SK-ES1 cell proliferation (Fig. $2 A$ ). The inhibition was maximal at bFGF concentrations (about $0.5 \mathrm{ng} / \mathrm{ml}$ ) that are known to induce maximal growth stimulation in other bFGF target cells (2). Surprisingly, it declined to control values at bFGF concentrations above $10 \mathrm{ng} / \mathrm{ml}$. The structurally and functionally related aFGF also inhibited SK-ES1 cell proliferation, but its concentrations required were about 500 -fold higher than those of bFGF (Fig. $2 A$ ). The structural specificity of growth inhibition was confirmed by the demonstration that other peptides, like epidermal growth factor, insulin, transferrin or the fibronectin fragment Gly-Arg-Gly-Asp-Ser-Pro-Lys (at concentrations ranging from 0.5 to $500 \mathrm{ng} / \mathrm{ml}$ ) had no effect on SK-ES1 cell proliferation (data not shown).

The bFGF-induced inhibition of SK-ES1 cell proliferation is reversible. When fresh medium or anti-bFGF antibodies were added to SK-ES1 cells that had been exposed to bFGF, either treatment, but not treatment with control antibodies, reversed the $b F G F-i n d u c e d$ inhibition of cell proliferation (Figs. $2 B$ and $C$ ). When bFGF was not added to SK-ES1 cells, 

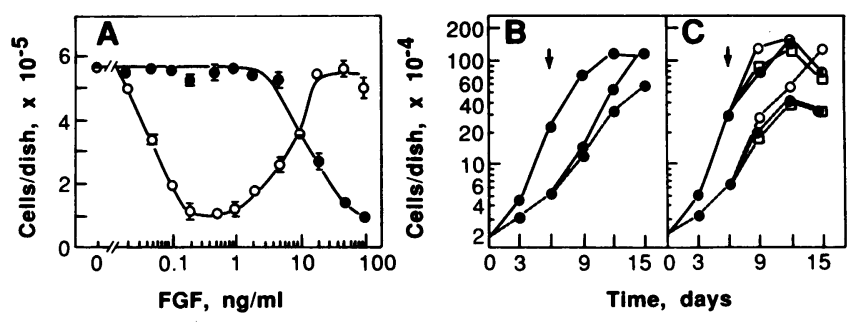

Figure 2. (A) Effect of various concentrations of bFGF or aFGF on the proliferation of SK-ES1 cells, and effect of $(B)$ medium exchange or $(C)$ antibodies on the bFGF-induced inhibition of SK-ES1 cell proliferation. SK-ES1 cells were seeded at a density of $2 \times 10^{4} /$ gelatinized 35-mm dish. $(A)$ Every other day, the cells received DMEM/0.5\% BSA containing no additions or pituitary-derived bFGF (9) (0) or brain-derived aFGF (11) (॰) to give the indicated final concentrations. Values represent the means $( \pm S D)$ of triplicate determinations. $(B)$ SK-ES1 cells received every other day DMEM/0.5\% BSA containing no additions (solid lines) or pituitaryderived bFGF (final concentration, $1 \mathrm{ng} / \mathrm{ml}$ ) (dashed lines). On day 6 (arrow), the medium was replaced by fresh medium and the cells then received DMEM/0.5\% BSA containing no additions (solid lines) or bFGF (final concentration, $1 \mathrm{ng} / \mathrm{ml}$ ) (dashed lines). (C) Every other day SK-ES1 cells received DMEM/0.5\% BSA containing no additions (solid lines) or pituitary-derived bFGF (final concentration, $1 \mathrm{ng} / \mathrm{ml}$ ) (dashed lines). From day 6 on, every other day they also received DMEM/0.5\% BSA containing either rabbit anti-bFGF antibodies $(0)$ or control antibodies $(\bullet)(6 \mu \mathrm{g}$ of protein $/ \mathrm{ml}$, respectively) or no additions (ם). Cells were counted after $7 \mathrm{~d}(A)$ or at the times indicated $(B$ and $C)$. Values in $B$ and $C$ represent the means of triplicate determinations (SD $<5 \%$ ).

the control antibodies had no effect on cell proliferation, whereas the anti-bFGF antibodies induced a slight increase in cell proliferation (Fig. $2 C$ ). Thus, the bFGF-induced inhibition of SK-ES1 cell proliferation is a reversible process and does not represent simple cytotoxicity.

bFGF also inhibited the proliferation of other tumor cell lines derived from Ewing's sarcoma, angiosarcoma, or osteosarcoma (Table I). However, bFGF did not inhibit, or did even stimulate, the proliferation of various other tumor cells (Table I). Thus, the bFGF-induced inhibition of cell proliferation is a cell-specific process.

Since inhibition of cell proliferation by certain growth factors can be due to an overexpression of growth factor receptors (20), we examined the binding of ${ }^{125}$ I-bFGF to SK-ES1 cells. Saturation binding studies demonstrated the existence of specific FGF receptors on the surface of SK-ES1 cells (Fig. $3 A$ ). Scatchard analysis of the binding interaction (Fig. $3 \mathrm{~A}$, inset) revealed the presence of about $14,000 \mathrm{FGF}$ receptors/SK-ES1 cell with an apparent dissociation constant of $76 \mathrm{pM}$, indicating no gross alteration of FGF receptor numbers or dissociation constant, as compared with other cell species, in which bFGF acts as a growth stimulator $(15,21,22)$. Bound ${ }^{125} \mathrm{I}-$ bFGF was displaced from the SK-ES1 cell surface receptors by unlabeled bFGF, but not by other peptides such as insulin, transferrin, or epidermal growth factor (at concentrations up to $200 \mathrm{ng} / \mathrm{ml}$ ) (not shown), indicating the specificity of the binding interaction. When ${ }^{125}$ I-bFGF was covalently crosslinked to the SK-ES1 cell surface, it labeled an $M_{\mathrm{r}}$ of 150,000 receptor species (Fig. $3 B$ ) that is similar in size to one of the two FGF receptor species $\left(M_{\mathrm{r}}\right.$ of 145,000 and 125,000 , respectively) previously demonstrated on BHK-21 cells $(15,21)$. ${ }^{125}$ I-bFGF binding to the $M_{\mathrm{r}}$ of 150,000 receptor on the SK-ES 1 cell surface was inhibited by the partially purified SK-ES1 cell extract or by unlabeled bFGF and likewise by anti-bFGF antibodies, but not by control antibodies (Fig. 3 B). Thus, SK-ES1 cells bear specific FGF receptors on their surface, to which their endogenous bFGF can bind and whereupon it probably exerts its inhibitory effect.

\section{Discussion}

We have demonstrated here that bFGF is present in cultured human Ewing's sarcoma cells, and that the endogenous bFGF can bind to FGF receptors on their surface and then inhibit cell proliferation. Inhibition is blocked by anti-bFGF antibodies, which do not cross-react with aFGF (14), whereas the

Table I. Effect of bFGF on the Proliferation of Various Tumor Cell Lines

\begin{tabular}{|c|c|c|c|c|}
\hline \multirow[b]{2}{*}{ Cell line } & \multicolumn{2}{|c|}{ Cells per dish $\left(\times 10^{-3}\right)( \pm \mathrm{SD})$} & \multirow{2}{*}{$\begin{array}{l}\text { Percent } \\
\text { stimulation }\end{array}$} & \multirow{2}{*}{$\begin{array}{l}\text { Percent } \\
\text { inhibition }\end{array}$} \\
\hline & -bFGF & $+\mathrm{bFGF}$ & & \\
\hline 5838 human Ewing's sarcoma & $241.0 \pm 1.3$ & $51.9 \pm 8.0$ & - & 78.5 \\
\hline D-14 mouse angiosarcoma & $528.6 \pm 14.4$ & $179.9 \pm 36.4$ & - & 66.0 \\
\hline D-10 mouse angiosarcoma & $657.9 \pm 8.2$ & $367.7 \pm 84.4$ & - & 34.0 \\
\hline U-2 OS human osteosarcoma & $682.7 \pm 60.3$ & $501.7 \pm 20.3$ & - & 26.5 \\
\hline A-431 human epidermoid carcinoma & $396.1 \pm 13.2$ & $395.2 \pm 24.7$ & - & 0.2 \\
\hline I-10 mouse Leydig cell tumor & $311.1 \pm 17.0$ & $315.8 \pm 18.2$ & 1.5 & - \\
\hline $\mathrm{GH}_{3}$ rat pituitary tumor & $421.5 \pm 35.3$ & $505.0 \pm 26.1$ & 19.8 & - \\
\hline A-204 human rhabdomyosarcoma & $932.6 \pm 36.2$ & $1259.3 \pm 18.6$ & 35.0 & - \\
\hline Y-1 mouse adrenal cortex tumor & $169.8 \pm 14.9$ & $600.2 \pm 54.8$ & 253.5 & - \\
\hline
\end{tabular}

All cell lines were seeded at a density of $4 \times 10^{4}$ per $35-\mathrm{mm}$ dish. The dishes contained the following media: D-14 (18); DMEM/10\% calf serum; D-10 (18); DMEM/10\% fetal calf serum (FCS); 5838 (19); RPMI 1640/20\% FCS. Media for all other cell lines were those recommended in the catalogue of the American Type Culture Collection (Rockville, MD). Every other day, dishes containing cells of the indicated cell lines received $10 \mu \mathrm{l}$ aliquots of either DMEM/0.5\% BSA only (-bFGF) or DMEM/0.5\% BSA containing bFGF (+bFGF) to give a final concentration of $1 \mathrm{ng}$ of $\mathrm{bFGF} / \mathrm{ml}$ of medium. After 4-6 d, the cells were trypsinized and counted with a counter (Coulter Electronics Inc.) (8). Values represent the means of three experiments $( \pm \mathrm{SD})$ performed in triplicate. 

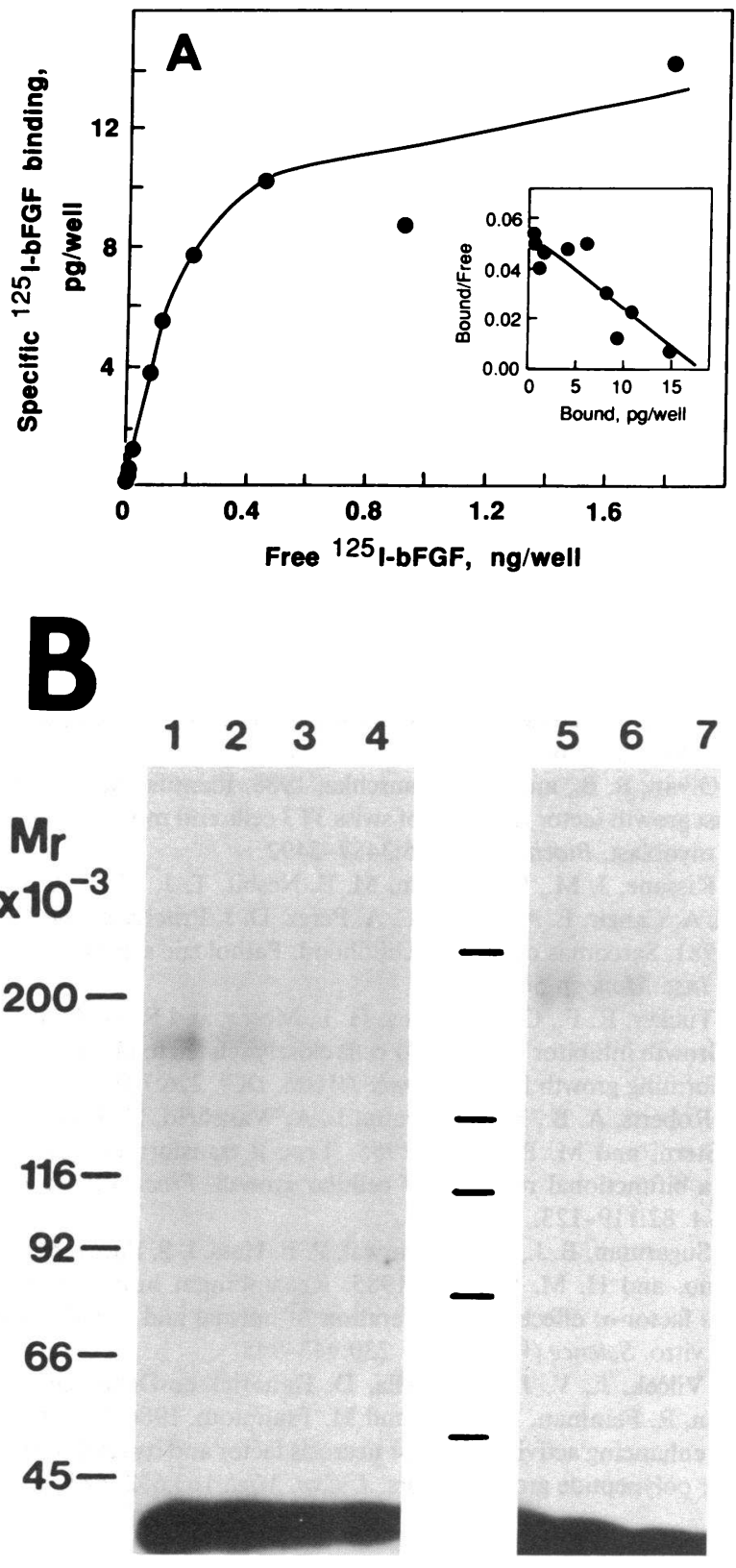

Figure 3. Analysis of ${ }^{125} \mathrm{I}-\mathrm{bFGF}$ binding to the SK-ES1 cell surface by $(A)$ saturation binding and $(B)$ cross-linking experiments. $(A)$ SK-ES1 cells $\left(8 \times 10^{5} /\right.$ gelatinized $16-\mathrm{mm}$ well $)$ and increasing concentrations of ${ }^{125} \mathrm{I}-\mathrm{bFGF}$ were incubated without or with unlabeled bFGF $(200 \mathrm{ng} / \mathrm{ml})$, and binding was then determined as described in Methods. Specific ${ }^{125} \mathrm{I}-\mathrm{bFGF}$ binding represents bound ${ }^{125} \mathrm{I}$-bFGF that was displaced by an excess $(200 \mathrm{ng} / \mathrm{ml})$ of unlabeled bFGF. Values are the means of triplicate determinations (SD < 5\%). (Inset) Scatchard analysis of the binding data. Bound/free ${ }^{125}$ I-bFGF is plotted as a function of specifically bound ${ }^{125} \mathrm{I}-\mathrm{bFGF}$. (B) SK-ES1 cells grown to confluence in gelatinized 5-cm tissue culture dishes were incubated for $3 \mathrm{~h}$ at $4^{\circ} \mathrm{C}$ with binding buffer (15) containing ${ }^{125} \mathrm{I}$ bFGF $(1 \mathrm{ng} / \mathrm{ml})$ and either no additions (lanes 1 and 5), partially purified SK-ES1 cell extract $(1.5 \mu \mathrm{g} / \mathrm{ml})$ (lane 2$)$, pituitary-derived bFGF ( 50 or $100 \mathrm{ng} / \mathrm{ml}$ ) (lanes 3 and 4 , respectively), control antibodies $(12 \mu \mathrm{g} / \mathrm{ml})$ (lane 6$)$, or anti-bFGF antibodies $(6 \mu \mathrm{g} / \mathrm{ml})$ (lane $7)$. Cells were then washed twice with PBS and cell surface-bound ligands were cross-linked using disuccinimidyl suberate $(0.2 \mathrm{mM})(15$, 21). Cells were lysed and radioactivity in the lysate was analyzed by noninhibited (basal) cell proliferation is stimulated by these antibodies. Thus, bFGF can act as an endogenous growth inhibitor for cultured Ewing's sarcoma cells in vitro.

The amounts of bFGF present in the Ewing's sarcoma cells (an equivalent of $200 \mathrm{ng} / 10^{9}$ cells) appear to be $\sim 60-100$-fold lower than those found in other cells $(3,14)$. This agrees with our observation that bFGF gene transcripts could not be detected (data not shown) by conventional Northern blot analyses $(3,14)$. However, a considerable amount of the intracellular bFGF might be released in vivo to exert its growth-inhibitory effect. This might occur upon cell leakage, e.g., in the frequently observed necrotic tumor areas, a feature highly characteristic for Ewing's sarcoma. In fact, the absence of necrosis mitigates against the diagnosis of Ewing's sarcoma (23). Characteristically, the mitotic activity in Ewing's sarcoma is minimal (23), suggesting that bFGF might act as a growth inhibitor for Ewing's sarcoma in vivo.

On the other hand, Ewing's sarcoma cells do probably produce other factors that support tumor growth, and that, in their entirety, might overcome the inhibitory effects of bFGF. Indeed, crude extracts prepared from SK-ES1 Ewing's sarcoma cells can stimulate SK-ES1 cell proliferation (Schweigerer, L., unpublished results).

bFGF acts as a mitogen for a wide variety of normal (2) or transformed ([2], Table I) mesoderm- or neuroectoderm-derived cells. As demonstrated here, bFGF can also act as a potent inhibitor of tumor cell proliferation. Thus, bFGF is a bifunctional regulator of tumor cell proliferation. It is not known, why bFGF acts as a growth stimulator in some tumor cell lines and as a growth inhibitor in others. However, as suggested in the case of other bifunctional regulators of cell growth (1, 24-27), the effect of bFGF on cell proliferation may be determined by the entire set of growth factors and their receptors operant in a cell line at a given time. Alternatively, growth inhibition might be due to structurally and/or functionally altered FGF receptors, that might confer growth-inhibitory, instead of growth-stimulatory signals.

The demonstration that bFGF can act as a growth inhibitor for certain human tumor cells is unexpected. It is tempting to speculate that these results might have implications for the treatment of these tumors.

\section{Acknowledgments}

We thank Dr. N. Sato for the gift of D-10 and D-14 angiosarcoma cells.

This study was supported by grants HL-20197 and EY-02186 from the National Institutes of Health, and by a fellowship from the Dr. Mildred-Scheel Foundation awarded to Dr. Schweigerer.

\section{References}

1. Sporn, M. B., and A. B. Roberts. 1985. Autocrine growth factors and cancer. Nature (Lond.). 313:745-747.

2. Gospodarowicz, D., G. Neufeld, and L. Schweigerer. 1986. Fibroblast growth factor. Mol. Cell. Endocr. 46:187-204.

3. Schweigerer, L., G. Neufeld, A. Mergia, J. A. Abraham, J. C. Fiddes, and D. Gospodarowicz. 1987. Basic fibroblast growth factor in

sodium dodecyl sulfate-polyacrylamide $(6 \%)$ gel electrophoresis and autoradiography as previously described $(15,21)$. Two gels with the corresponding size markers are shown. 
human rhabdomyosarcoma cells: implications for the proliferation and neovascularization of myoblast-derived tumors. Proc. Natl. Acad. Sci. USA. 84:842-846.

4. Triche, T. J. 1982. Round cell tumors in childhood: the application of newer techniques to the differential diagnosis. Perspect. Pediatr. Pathol. 7:279-322.

5. Variend, S. 1984. Small cell tumors in childhood: a review. $J$. Pathol. 145:1-25.

6. Vlodavsky, I., G.-M. Lui, and D. Gospodarowicz. 1980. Morphological appearance, growth behavior and migratory activity of human tumor cells maintained on extracellular matrix versus plastic. Cell. 19:607-616.

7. Gospodarowicz, D., G.-M. Lui, and R. Gonzalez. 1982. Highdensity lipoproteins and the proliferation of human tumor cells maintained on extracellular matrix-coated dishes and exposed to defined medium. Cancer Res. 42:3704-3713.

8. Gospodarowicz, D., S. Massoglia, J. Cheng, and D. K. Fujii. 1986. Effect of fibroblast growth factor and lipoproteins on the proliferation of endothelial cells derived from bovine adrenal cortex, brain cortex and corpus luteum capillaries. J. Cell. Physiol. 127:121-136.

9. Gospodarowicz, D., J. Cheng, G.-M. Lui, A. Baird, and P. Böhlen. 1984. Isolation by heparin-Sepharose affinity chromatography of brain fibroblast growth factor: identity with pituitary fibroblast growth factor. Proc. Natl. Acad. Sci. USA. 81:6963-6967.

10. Lobb, R. R., J. W. Harper, and J. W. Fett. 1986. Purification of heparin-binding growth factors. Anal. Biochem. 154:1-14.

11. Böhlen, P., F. Esch, A. Baird, and D. Gospodarowicz. 1985. Acidic fibroblast growth factor from bovine brain. Amino-terminal sequence and comparison to basic fibroblast growth factor. $E M B O$ (Eur. Mol. Biol. Organ.) J. 4:1951-1956.

12. Weber, E., C. J. Evans, J.-K. Chang, and J. D. Barchas. 1982. Antibodies specific for $\alpha$ - $\mathrm{N}$-acetyl- $\beta$-endorphins: radioimmunoassays and detection of acetylated $\beta$-endorphins in pituitary extracts. $J$. Neurochemistry. 38:436-447.

13. Goding, J. W. 1976. Conjugation of antibodies with fluorochromes: modification to the standard methods. J. Immunol. Meth. 13: $215-226$.

14. Schweigerer, L., G. Neufeld, J. Friedman, J. A. Abraham, J. C. Fiddes, and D. Gospodarowicz. 1987. Capillary endothelial cells express basic fibroblast growth factor, a mitogen that promotes their own growth. Nature (Lond.). 325:257-259.

15. Neufeld, G., and D. Gospodarowicz. 1985. The identification and partial characterization of the fibroblast growth factor receptor of baby hamster kidney cells. J. Biol. Chem. 260:13860-13868.

16. Gospodarowicz, D. 1984. Preparation of extracellular matrices produced by cultured bovine corneal endothelial cells and PF HR-9 teratocarcinoma cells: their use in the study of cell proliferation and differentiation. In Methods in Molecular and Cell Biology. Vol. 1. D. Barnes, D. Sirbasku, and G. Sato, editors. A. R. Liss, New York. 275-294.

17. Esch, F., N. Ueno, A. Baird, F. Hill, L. Denoroy, N. Ling, D. Gospodarowicz, and R. Guillemin. 1985. Primary structure of bovine brain acidic fibroblast growth factor (FGF). Biochem. Biophys. Res. Commun. 133:554-562.

18. Sato, N., T. Sato, S. Takahashi, and K. Kikuchi. 1986. Establishment of murine endothelial cell lines that develop angiosarcomas in vivo: brief demonstration of a proposed animal model for Kaposi's sarcoma. Cancer Res. 46:362-366.

19. Fogh, J., J. M. Fogh, and T. Orfeo. 1977. One hundred and twenty-seven cultured human tumor cell lines producing tumors in nude mice. J. Natl. Cancer Inst. 59:221-226.

20. Lipshitz, A., C. S. Lazar, J. E. Buss, and G. Gill. 1983. Analysis of morphology and receptor metabolism in clonal variant A431 cells with differing growth responses to epidermal growth factor. J. Cell. Physiol. 115:235-242.

21. Neufeld, G., and D. Gospodarowicz. 1986. Basic and acidic fibroblast growth factors interact with the same cell surface receptors. J. Biol. Chem. 261:5631-5637.

22. Olwin, B. B., and S. D. Hauschka. 1986. Identification of the fibroblast growth factor receptors of swiss 3T 3 cells and mouse skeletal muscle myoblast. Biochemistry. 25:3487-3492.

23. Kissane, J. M., F. B. Askin, M. E. Nesbit, T. J. Vietti, E. O. Burgert, A. Cangir, E. A. Gehan, C. A. Perez, D. J. Pritchard, and M. Tefft. 1981. Sarcomas of bone in childhood: Pathologic aspects. Natl. Cancer Inst. Monogr. 56:29-41.

24. Tucker, R. F., G. D. Shipley, H. L. Moses, and R. W. Holley. 1984. Growth inhibitor from BSC-1 cells closely related to platelet type $\beta$ transforming growth factor. Science (Wash. DC). 226:705-707.

25. Roberts, A. B., M. A. Anzano, L. A. Wakefield, N. S. Roche, D. F. Stern, and M. B. Sporn. 1985. Type $\beta$ transforming growth factor: a bifunctional regulator of cellular growth. Proc. Natl. Acad. Sci. USA. 82:119-123.

26. Sugarman, B. J., B. B. Aggarwal, P. E. Hass, I. S. Figari, M. A. Palladino, and H. M. Shepard. 1985. Recombinant human tumor necrosis factor- $\alpha$ : effects on proliferation of normal and transformed cells in vitro. Science (Wash. DC). 230:943-945.

27. Vilček, J., V. J. Palombella, D. Hendricksen-DeStefano, C. Swenson, R. Feinman, M. Hirai, and M. Tsujimoto. 1986. Fibroblast growth enhancing activity of tumor necrosis factor and its relationship to other polypeptide growth factors. J. Exp. Med. 163:632-643. 